\title{
EFFECT OF COMMONLY PRESCRIBED ANTIBIOTICS ON MARGINAL ADAPTATION OF GLASS IONOMER RESTORATION: AN IN VITRO STUDY
}

\author{
Bothaina Ahmed Ibrahim*, Amr Mahmoud Abdel Aziz ${ }^{* *}$ and Reham Khaled Elghazawy***
}

\begin{abstract}
Aim: The purpose of this study was to determine the three most commonly prescribed antibiotics in a group of Egyptian Pediatricians. These antibiotics were evaluated regarding their effect on marginal adaptaion of glass ionomer restoration.
\end{abstract}

Materials and Method: First, a questionnaire was conducted in two large hospitals in Egypt (Aldemrdash hospital representing Ain Shams University and Qena public hospital) among a group of Egyptian pediatricians $(n=150)$ to determine the three most commonly prescribed antibiotics there. The three antibiotics were Duricef, E-moxclav and Suprax. Artificial saliva was also used in this study as a control. Second, $\mathrm{pH}$ and titratable acidity of the all used solutions were measured. Class I cavity was prepared for all teeth then they were restored with self adhesive glass ionomer restoration (Equia ${ }^{\mathrm{TM}} \mathrm{Fil}$ ). Teeth were thermocycled then they were randomly divided into four groups for drug immersion for 14 days with daily change of the solution. Teeth then were prepared for staining with methyle blue dye.

Results: According to scoring criteria of Khera and Chanas, Score 1 was for Duricef and E-moxclav groups while score 2 was for Suprax group. Score 0 was for control group.

Conclusion: Antibiotics commonly used for children had negative effect on marginal adaptation of glass ionomer restoration.

\section{INTRODUCTION}

Children are the long run of our society and ensuring their overall physiologic state is of outmost importance. The mouth is the mirror of our body and also the oral health is important for children's growth, development and general health. Although dental caries is that the most prevalent infectious disease in the oral cavity, dental erosion is additionally quite common and has deleterious effect on tooth structure. ${ }^{(1)}$

\footnotetext{
* Post graduate student from Misr University for Science and Technology and Master candidate in Department of Pediatric Dentistry and Dental Public Health, Faculty of Dentistry Ain Shams University.

** Professor and head of Pediatric Dentistry and Dental Public Health Department, Faculty of Dentistry Ain Shams University. *** Lecturer of Pediatric Dentistry and Dental Public Health, Faculty of Dentistry Ain Shams University
} 
Dental erosion is defined as progressive loss of dental hard tissues by chemical dissolution without bacterial involvement. In modern societies, changing lifestyle has contributed to an increased incidence of dental erosion especially in children and adolescents. Erosive tooth wear could be multifactorial irreversible process that will be caused by intrinsic, extrinsic or idiopathic factors. ${ }^{(1)}$

Intrinsic factors are because of contact of tooth structure with stomach acids. Extrinsic sources of dental erosion are mainly acidic food and drinks consumption. Acidic oral medicines are extrinsic etiologic factors for dental erosion. ${ }^{(1)}$

Liquid oral medications are usually prescribed for youngsters to beat difficulty encountered in other forms like tablets. These oral medicines are acidic preparations (mainly citric acid is used) as the acids are often necessary for drug dispersion, chemical stability maintenance, to ensure physiologic compatibility and to enhance flavor. ${ }^{(1,2)}$

In addition to the acidic components (low $\mathrm{pH}$ and high titratable acidity), other factors like prolonged and frequent ingestion (i.e., two or more times daily), bedtime, between meals consumption, high viscosity and also the collateral effect of reduced salivary flow may contribute to increasing the danger for medication-induced dental erosion. ${ }^{(1,2,3)}$

Erosion can affect both deciduous and permanent teeth. It starts with softening tooth surface (enamel) and progresses to extensive loss of tooth substance. (3) Deciduous enamel is different from permanent enamel because the former is less mineralized and has greater organic content than the latter that ends up in different erosive pattern between them. Children who are initially presented with erosive lesions in deciduous teeth have a significantly greater risk of getting erosive lesions in their permanent teeth. Health professionals should be fully conscious of the erosive effect of various medications on deciduous and permanent enamel. ${ }^{(4)}$
Many liquid medications are often a part of the daily routine of children with chronic diseases. Antibiotics are the foremost common sugar- containing drugs used for young children. These acidic medications affect both tooth structure and dental restorations like glass Ionomer restorations and they may result in gap formation between tooth and restoration and accordingly failure. ${ }^{(3,5-7)}$

The unwise and over prescription of antibiotics in children can affect children oral and general health. Appropriate antibiotic stewardship includes proper selection, dose and duration of the treatment to stop any undesirable effect. ${ }^{(8,9,10)}$

There is lack of evidence concerning the effect of the antibiotics on primary teeth and dental restorations, therefore this study aimed to clarify these points.

\section{MATERIALS AND METHOD}

\section{Ethical Approval:}

The ethical approval for this research was obtained from the ethical committee, Faculty of Dentistry, Ain Shams University. The approval number was:FDASU-Rec EM 210148.

\section{Questionnaire:}

A cross sectional questionnaire was conducted in two hospitals (Aldemrdash hospital representing Ain Shams University and Qena public hospital) in a group of Egyptian pediatricians $(n=150)$ to determine the three most commonly prescribed antibiotic syrups for children with age group 2-5 years.

\section{Sample size estimation:}

They were 150 pediatricians (70 doctors in Aldemrdash hospital and 80 doctors in Qena public hospital) that were surveyed. The sample size was estimated using Epicalc programme version 1.02 assuming a power of $80 \%$ and alpha $=0.05$. 
This estimation was based on the number of the specialists working in these two hospitals who agreed to participate in this questionnaire.

\section{SURVEY FOR ANTIBIOTIC PRESCRIPTION}

1. Name of the participant:

2. Work experience in years:
a. clinical practice
b. Academic
c. both

3. How many pediatric patients do you treat on an average per day?.......

4. What are the three most commonly prescribed antibiotics by you?

5. What is the duration of the antibiotic course?
a. 3 days
b. 5 days
c. 7 days
d. 10 days
If there is any comment please add:

6. What is the frequency of prescription per week?

7. Do you routinely prescribe antibiotics in the following conditions?
a. common cold
Yes/No
b. influenza (flu)
$\mathrm{Yes} / \mathrm{No}$
c. otitis media
Yes/No
d. runny nose
Yes/No

8. Are you aware of the current guidelines for antibiotic prescription? Yes/No

9. Are you aware of the term "antibiotic resistance"? Yes/No

10. Self-medications with antibiotics by patient may be responsible for antibiotic resistance? Yes/No /not sure

11. Do you inquire from your patient about whether he/she has taken a course of antibiotic in the past 1 week before prescription? Yes/No

12. Do you advise the patient to adhere to dosage regimen? Yes/No
13. Do you prescribe antibiotic in these situations?

a. When the parent insists to prescribe antibiotic

b. To sustain the patient till the specialist treats that patient

c. To defer treating the patient because you have appointments waiting

\section{Materials}

\section{Antibiotics:}

Based on the above questionnaire the three most commonly prescribed antibiotics were:

- Duricef:

- E-moxclav:

- Suprax:

\section{Artificial saliva:}

Artificial saliva was prepared in the laboratory of Zoology Department at Faculty of Science in South Valley University.

\section{Methods:}

Measurement of $\mathrm{pH}$ and titratable acidity:

\section{- Measurement of pH:}

The $\mathrm{pH}$ of pediatric medicated syrups and artificial saliva was measured using a digital $\mathrm{pH}$ meter $20 \mathrm{ml}$ of each medicated syrup in a glass beaker which was placed in a thermostatically controlled water bath at $37^{\circ} \mathrm{C}$ and a glass electrode was inserted into the syrup which displayed $\mathrm{pH}$ on the meter. Each sample was tested three times to record a mean measurement. ${ }^{(11)}$

\section{- Measurement of Titratable acidity:}

The titratable acidity of syrups and artificial saliva was measured by placing $20 \mathrm{ml}$ of the product in a glass beaker placed in a thermostatically controlled water bath at $37^{\circ} \mathrm{C}$. Then, $0.1 \mathrm{M}$ sodium hydroxide solution was gradually pipetted into the beaker until the $\mathrm{pH}$ reaches neutral and the samples were stirred continuously. ${ }^{(11)}$ 
The volume of sodium hydroxide required to increase the $\mathrm{pH}$ of the sample to neutrality was recorded; and the process was repeated three times for each sample to record a mean measurement. It was measured in the chemistry labs in Faculty of Science at South Valley university.

Titratable acidity was calculated by the following equation:

$\%$ acid $=$

(mls NAOH used) x (.1 N NAOH) x (milliequivalent factor) $x 100$ grams of sample

Teeth selection, Grouping, cleaning and preparation

A total of forty sound human primary teeth were collected to be used for this invitro study.

\section{- Sample size estimation:}

Epicalc programme version 1.02 assuming a power of $80 \%$ and alpha $=0.05$ was used.

The selected forty primary molars were cleaned with pumice using polishing brush at low speed to remove any debris. Cavity class I $1.5 \times 2 \times 2 \mathrm{~mm}$ was prepared for all teeth using 330 carbide bur at high speed with air -water spray. Then the forty teeth were restored with self adhesive glass ionomer Equia ${ }^{\mathrm{TM}}$ fil according to the manufacture's instructions. Teeth were thermocycled between $5^{\circ} \mathrm{C}$ and $55^{\circ} \mathrm{C}$ water bath for 250 cycles. $^{(5)}$

The forty teeth were randomly divided into four groups for immersion in the specific solutions for 14 days with daily change of the solution.

Group E: 10 teeth for immersion in Duricef

Group F :10 teeth for immersion in E-moxclav

Group G: 10 teeth for immersion in Suprax

Group $\mathrm{H}$ : 10 teeth for immersion in artificial saliva.

\section{- Teeth Staining and Sectioning:}

Specimens were then prepared for staining. The apex of each tooth was sealed with wax and the surface of each tooth (except $1 \mathrm{~mm}$ around the restoration margin) was covered with two layers of nail polish then immersed in a solution of $1 \%$ methylene blue dye for 24 hours at room temperature.

Subsequently, the specimens were taken out of the solution, washed with water and the samples were mounted onto special holding device for sectioning. ${ }^{(5)}$

Teeth were sectioned mesiodistally with a low speed diamond stone under water spray. The specimens were rinsed under running water the dried with tissue paper. ${ }^{(5)}$

The dye penetration along the cavity wall (including both axial and gingival margins) was assessed with a measuring Stereomicroscope (Nikon Eclips E600, Tokyo ,Japan) at 35x magnification in which the image was captured and the transferred to a computer equipped with image analysis software program (Image J1.43U, National Institute of Health, USA), where the leakage was assessed. Microleakge criteria was determined according to scores described by Khera and Chans ${ }^{(12)}$, (Table 1)

TABLE (1): Scoring criteria by Khera and Chanas ${ }^{(12)}$

\begin{tabular}{|c|l|}
\hline Scoring & Criteria \\
\hline 0 & No leakage \\
\hline 1 & Dye penetration extending $1 / 3^{\text {rd }}$ of the cervical wall \\
\hline 2 & Dye penetration extending $2 / 3^{\text {rd } \text { of the cervical wall }}$ \\
\hline 3 & $\begin{array}{l}\text { Dye penetration up to the junction of the axial and } \\
\text { occlusal or cervical wall }\end{array}$ \\
\hline 4 & Dye penetration include the axial wall \\
\hline
\end{tabular}




\section{RESULTS}

\section{Results of pH and titratable acidity:}

Suprax syrup had the lowest $\mathrm{pH}$ and highest titratable acidity, followed by Duricef then E-moxclav while artificial saliva had almost neutral $\mathrm{pH}$ and the lowest titratable acidity as shown in table 2

TABLE (2) $\mathrm{pH}$ and titratable acidity of the three common antibiotics and artificial saliva $\mathrm{P}<0.05$ by two-way ANOVA test

\begin{tabular}{|c|c|c|}
\hline Solution & $\begin{array}{c}\mathrm{pH} \\
\operatorname{mean}( \pm \mathrm{SD})\end{array}$ & $\begin{array}{l}\text { Titratable Acidity } \\
\text { mean }(\mathrm{ml})( \pm \mathrm{SD})\end{array}$ \\
\hline Duricef & $4.87 \pm 0.01$ & $1.47 \pm 0.15$ \\
\hline E-moxclav & $4.55 \pm 0.03$ & $5.23 \pm 0.21$ \\
\hline Suprax & $3.53 \pm 0.09$ & $5.40 \pm .56$ \\
\hline Artificial Saliva & $6.8 \pm 0.1$ & $0.20 \pm 0.10$ \\
\hline
\end{tabular}

\section{II.Microleakge results:}

The depth of dye penetration in enamel and dentin was an indication of marginal microleakge. The results obtained were analyzed for statistical analysis using one- way AVOVA ,Frideman test ranks (table 3)

\section{Microleakage score for each test media:}

Suprax was the most acidic drug and that resulted in more dye penetration along the margins of the restoration (up to $2 / 3^{\text {rd }}$ of the cervical wall) recording score 2. Duricef and E-moxclav had lower acidity than Suprax so dye penetration was only up to $1 / 3^{\text {rd }}$ of the cervical wall which was score 1 for these two drugs.

These results proved that the three acidic drugs can affect the integrity of self adhesive glass ionomer restoration (Equia ${ }^{\mathrm{TM}}$ Fil). Margins defects was more in Suprax (the most acidic drug) than Duricef and E-moxclav. In case of control group of artificial saliva there was no dye penetration (score 0 ) which meant intact margins

TABLE (3): Scoring for each subgroup.

\begin{tabular}{|l|l|l|}
\hline Scoring & Test media & P value \\
\hline 0 (figure 1) & Artificial saliva & $0.000^{* *}$ \\
\hline 1 (figure 2) & Duricef & $0.023^{*}$ \\
\hline 1(figure 3) & E-moxclav & $0.002^{*}$ \\
\hline 2 (figure 4,5) & Suprax & $0.001 *$ \\
\hline
\end{tabular}

* Significant. ** Highly significant

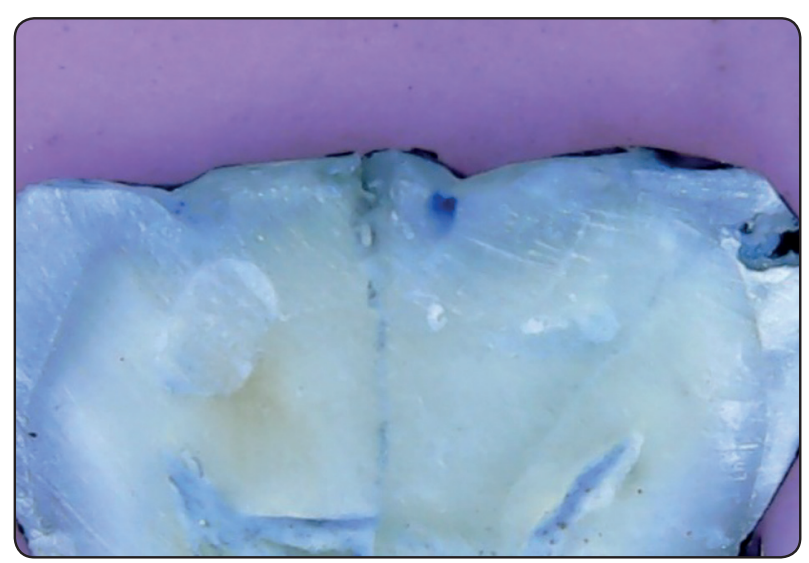

Fig. (1) Dye penetration with 0 score for group H (artificial saliva)

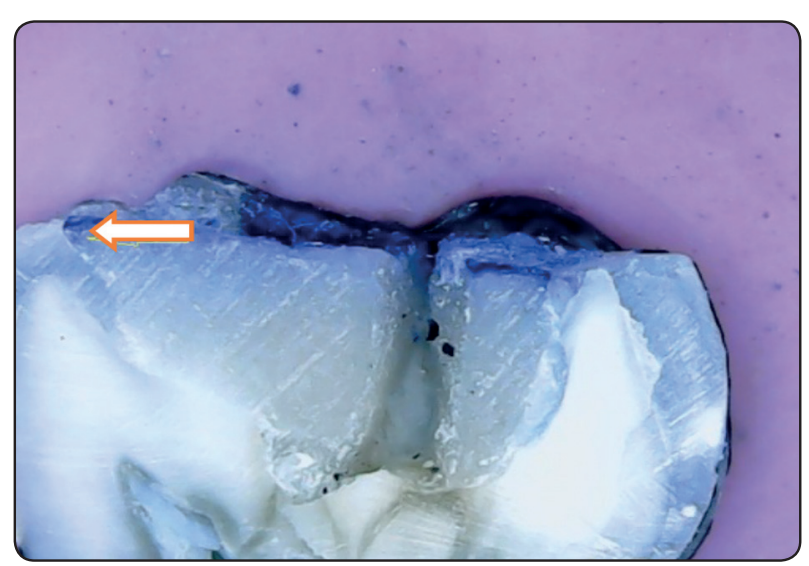

Fig. (2) Dye penetration with score 1 for group E (Duricef) 


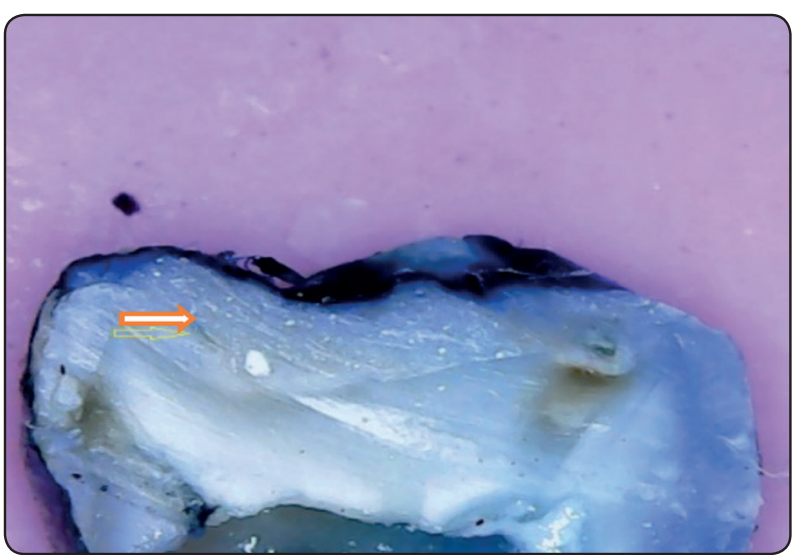

Fig. (3) Dye penetration with 1 score for subgroup F (E-moxclav)

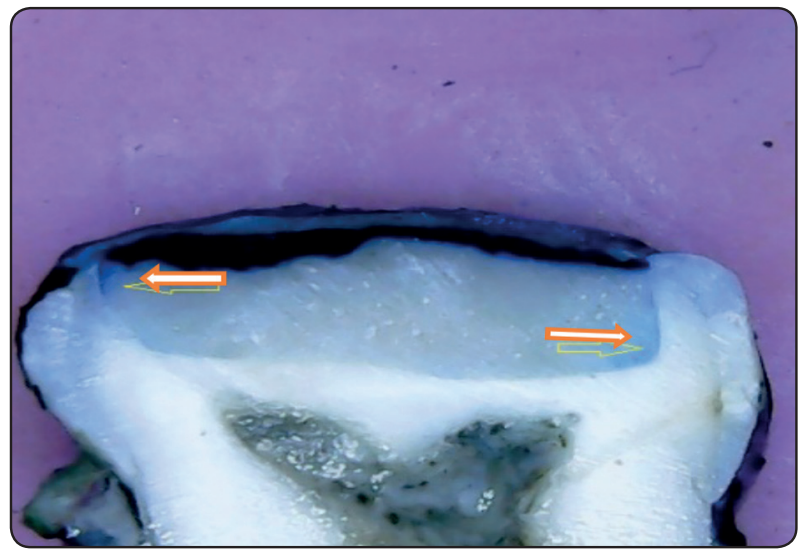

Fig. (4) Dye penetration with score 2 for subgroup G (Suprax)

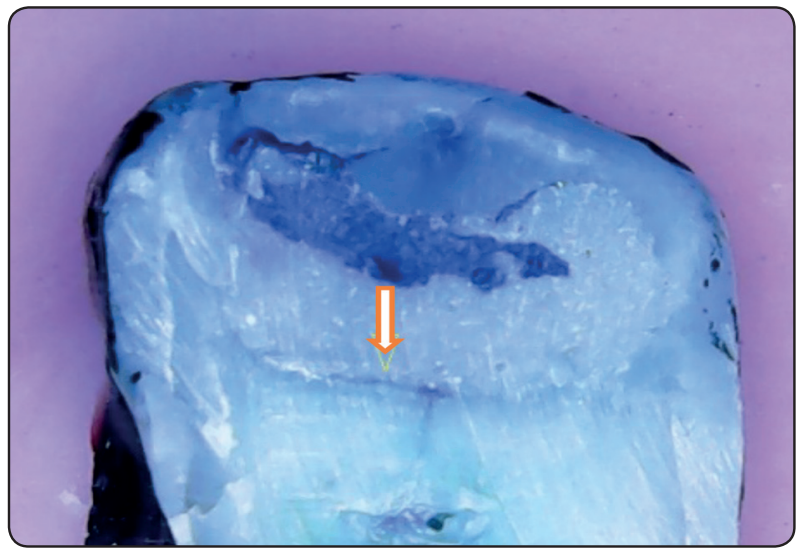

Fig. (5) Dye penetration with 2 score for subgroup G (Suprax)

\section{DISCUSSION}

Dental caries is the most typical disease of the oral cavity and may affect individuals at different stages of life. However, teeth dissolution may be also due to erosion, which is that, the mineral loss of dental tissues when teeth surfaces are exposed to acids or chelates in a systematic manner without bacterial involvement. ${ }^{(1)}$

The prevalence of dental erosion increases among children and adolescents. This is often because of frequent use of the many products with acidic content like medications used for treatment of chronic diseases as antihistamine containing syrups and also medications used for treatment of infections which are antibiotics. ${ }^{(11)}$

Many antibiotics have been introduced and are commonly prescribed for various childhood infections. Amoxicillin and cephalosporin are used widely among children for treatment of several infections like otitis media. Many of these medical syrups have some inactive ingredients with acidic nature to reinforce drug dispersion and for chemical stability. ${ }^{(3)}$

The erosive effect of several acid preparations on tooth surface can be influenced by many factors including $\mathrm{pH}$, titratable acidity, temperature, acid character, concentration and chelation potential. There are other factors like frequency, timing of the intake and duration of the exposure in the mouth ${ }^{(3)}$. In addition to these factors, pellicle layer and variation in tooth structure may also contribute to dental erosion.

Most of the medicinal syrups like antibiotics have low $\mathrm{pH}$ due to acidic content and most of those $\mathrm{pH}$ values are below the critical $\mathrm{pH}(\mathrm{pH}<5.5)$, therefore the unwise prescription of antibiotics by pediatricians and overuse of those medical syrups increase the danger of dental erosion and gap formation between the teeth margins and dental restoration.

This study was conducted to clarify the effect of antibiotics prescribed commonly by Egyptian pediatricians on marginal adaptation of glass 
ionomer restoration. Our study was an in-vitro experimental study where extracted primary teeth were used for microleakage test.

First, a survey was conducted in two large different hospitals in Egypt (Aldemrdash hospital representing Ain Shams University and Qena public hospital) in a group of Egyptian pediatricians $(n=150)$ to determine the categories of the prescribed antibiotics. From the questionnaire, we used the data of the three most commonly prescribed antibiotics and also we got an idea about the misuse of the antibiotics among the Egyptian pediatricians. We will use the rest of the data in further research work.

We selected Aldemrdash as it is a large hospital in Cairo and Qena public hospital as it is a large hospital in Upper Egypt. These two hospitals had the advantage of the high flow of patients there to increase the significance of the survey. Moreover, these two hospitals are in two different regions to assess if there is difference in the pattern of antibiotic prescription among different regions or not.

According to our survey the three most commonly prescribed antibiotics were Duricef, E-moxclav and Suprax. The acidic inactive ingredients of these medications have direct effect in drug $\mathrm{pH}$ and titratable acidity, so the unwise prescription of antibiotics by pediatricians and overuse of these medical syrups increase the risk of dental erosion and failure of the restorations. These three antibiotics have inactive ingredients that lead to increase their acidity. Suprax (cefixime) has acetic acid (triacetin) as an inactive ingredient in this drug formulation. Xanthan gumtheticm used as in active ingredient for Duricef (cefadroxil) has both glucuronic acid and pyruvic acid in its composition. In case of E-moxclav, succinic acid is used in drug formulation. ${ }^{(13-15)}$

Drug $\mathrm{pH}$ and tiratble acidity are critical because they can directly affect the marginal integrity of glass ionomer restorations ${ }^{(11)}$. In this experimental study, the $\mathrm{pH}$ and titratable acidity of the all drugs were measured.
Suprax showed the lowest $\mathrm{pH}$ and the highest titratable acidity, so it is the most acidic drug, followed by E-moxclav. Duricef had the highest $\mathrm{pH}$ and the lowest titratable acidity of the drugs. In our study, artificial saliva was used as control. It had almost neutral $\mathrm{pH} .{ }^{(16)}$

Before drug immersion, the samples were thermocycled between $5^{\circ}$ and $55^{\circ} \mathrm{C}$ for 250 cycles. Thermocycling is an important procedure as the samples were exposed to temperature ranges similar to those occur in the oral cavity. This had a value of increasing the significance of the results. ${ }^{(5)}$

Forty teeth were randomly divided into four subgroups for drug immersion for 14 days with daily change of the solution. ${ }^{(5)}$ After that staining, process with methylene blue dye was made for 24 hours to assess the microleakage using stereomicroscope. Using of stereomicroscope has many benefits. By using stereomicroscope, we can get the best threedimensional image of the objects. It also has many options of adjusting the focus this lead to get more magnified and clear samples. ${ }^{(11)}$

Microleakage was mostly detected in Suprax group as it recorded score 2, that meant methylene blue dye penetration was up to the $2 / 3^{\text {rd }}$ of the cervical wall. That was because Suprax was the most acidic drug that led to more marginal degradation than the other two drugs.

Score 1 was recoeded for both E-moxcalv and Duricef group., that meant methylene blue dye penetration is up to $1 / 3^{\text {rd }}$ of the cervical wall. No leakage was detected in control group of artificial saliva which meant that there was no penetration of methylene blue dye as the margins were intact. This proved that the three acidic medications can affect the integrity of the dental restoration.

In agreement to these results, many studies supported the evidence that acidic medical syrups can affect the integrity of different dental restorations. In 2020, in Isatnbul Turkey a study proved that the prolonged use of pediatric medicines had negative effect on physical properties of the restorative 
materials. ${ }^{(17)}$ Other studies pointed that different medical syrups, beverages and dietary substances affected the integrity of dental restorations like glass ionomer restoration and nano-filled composite. ${ }^{(18,19)}$

\section{REFERENCES}

1. Gaurao V., Arun S., et al. Effect of conventional and sugar free pediatric syrup formulations on primary tooth enamel hardness. J Indian Soc Pedod Prev Dent. 2015 Oct-Dec; 33(4):331-6.

2. Da Silva Pierro VS, Maia LC, et al., Effect of Dilution on the PH and Titratable Acidity of Pediatric Syrup Medicines. scientificreports 595 (2013). Doi 10.4172.

3. Cavalcanti AL, Fernandes LV., et al. Titratable acidity and total soluble solid content of pediatric antitussive medicines. Acta Stomatol Croat 2008; 42:164-70

4. Lussi A. Thiago S. Analyses of the erosive effect of dietary substances and medications on deciduous teeth. Journal. pone (2015) 10 (12).

5. Rosangela M., Juan S, et al; Assessment of GIC restorations after acidic erosive challenges Pesquisa Brasileira em Odontopediatria e Clínica Integrada 2016, 16(1):323-330

6. Salama F., Riad M.,et al . Microleakage and marginal gap formation of glass ionomer resin restoration. J Clin Pediatr Dent 1995;20(1):31-36

7. Walton, R. Microleakage of restorative materials. Oper Dent 1987;138-9.

8. Noraziad Ab.Rahman, Cheong L., et al. Antibiotic prescription in public and private practice: a cross sectional study in Malasyia. (2016) 16:208 DOI 10.1186/s12879-016-1530-2.

9. Osama H. Mohamed Ibrahim. Evaluation of Drugs and Antibiotic Utilization in an Egyptian University Hospital: An Interventional Study, 2012,2:2 .Doi.org/10.4172/21658048.1000109.

10. Spna K., Lalitha S., et al. Antibiotic overusage and resistance: A cross-sectional survey among pediatric dentists DOI:10.4103/0970-4388.18044
11. Krishna T, Vijay B, Mahadevan G et al. Erosive potential of commonly used beverages, medicated syrup, and their effects on dental enamel with and without restoration. 2015 Journal of Pharmacy and Bioallied science. DOI: 10.4103/0975-7406.163508

12. S C Khera, K C Chan. Microleakage and enamel finish, PMID: 273692. DOI: 10.1016/s002-3913(78)80159-0

13. Mohamed EM. and Mahmoud A. Comparative In-Vitro Dissolution Studies for Determination of Cefixime in an Innovator Product of Suprax Powder for Oral Suspension Dosage form Using Rp-Hplc Method. 2018 GlobJ.Otolaryngol. Doi:10.19080/GJO.2018.14.555886

14. Badawy SS, Abdel-Gawad FM. Spectrophotometric studies on Determination of Cefadroxil with copper(II) and Vandium (V) in Sulphuric Acid Medium 23 Sep 2006 Analytical letter. Doi: 10.1080/000327193080168

15. ElSayed M, Ammar A, et al. Virulence Reprtoire of pseudomaonas aeruginosa from some poultry farms with Detection of Resistance to Various Antimicrobials and plant Extracts. 2016 Cellular and Molecular Biology. Doi: 10.4172/1165-158X.1000124

16. Baris A, Abdillah I, et al . The $\mathrm{pH}$ changes of artificial saliva after interaction with oral of artificial saliva after interaction with oral micropathogen. 2012Dental Journal (Majalah Kedokteran Gigi) .DOI: 10.20473/j.djmkg.v45. i4.p234-238

17. Elif B, Gokcen D. Effect of pediatric multivitamins and effervescent tablets on the surface microhardness and roughness of restorative materials. J of dental science April 2020 Doi:1010/16j.jds .2020.03.017.

18. Magnur PC, Prabhkar AR, et al. Erosive effect of Soft Drink and Fresh Fruit Juice on Restorative Materials. World J Dent 2013;4(1):32-40

19. Khan AA, Siddiqui AZ, et al. Effect of different $\mathrm{pH}$ solvents on microhardness and surface topography of dental nan0-composite: An in vitro study. Pak J Med Sci 2015;31(4):854-859 